\title{
Preliminary Identification of the Bioremediation Limiting Factors of a Clay Bearing Soil Contaminated with Crude Oil
}

\author{
Andréa C. L. Rizzo, ${ }^{* a}$ Claudia D. da Cunha, ${ }^{a}$ Ronaldo L. C. Santos, ${ }^{a}$ Renata M. Santos, ${ }^{a}$ \\ Hugo M. Magalhães, ${ }^{a}$ Selma G. F. Leite ${ }^{b}$ and Adriana U. Soriano ${ }^{c}$
}
${ }^{a}$ Centro de Tecnologia Mineral (CETEM/MCT), Av. Pedro Calmon, 900, Cidade Universitária, 21941-908 Rio de Janeiro-RJ, Brazil
${ }^{b}$ Departamento de Engenharia Bioquímica (EQ), Universidade Federal do Rio de Janeiro, Cidade Universitária, 21949-900 Rio de Janeiro-RJ, Brazil
'CENPES/Petrobras, Av. Horácio Macedo, 950, Cidade Universitária, 21941-598 Rio de Janeiro-RJ, Brazil

\begin{abstract}
A biorremediação é uma alternativa atraente para o tratamento de solos contaminados com hidrocarbonetos de petróleo. No entanto, a efetividade do processo pode ser limitada não só pelas características do contaminante, mas também pela sua biodisponibilidade. Este trabalho tem como meta o estabelecimento de procedimento preliminar para identificar o fator principal (recalcitrância ou biodisponibilidade) que interfere negativamente na biodegradação, resultando em baixas eficiências. Foram realizados testes em microcosmos contendo solo aplicando as técnicas de bioestímulo e bioaumento. Experimentos semelhantes foram conduzidos em meio líquido contendo óleo cru e microorganismos extraídos do solo contaminado, nutrientes e inóculo microbiano (Rhodoturula glutinis e Nocardia nova). Após 30 dias, o maior nível de biodegradação (98.8\%) foi obtido na condição com bioaumento em meio líquido, indicando que o problema principal de biodegradação de hidrocarbonetos de petróleo pode estar associado à baixa biodisponibilidade destes no solo e não apenas a recalcitrância intrínseca do poluente residual.
\end{abstract}

Bioremediation is an attractive alternative to treat soils contaminated with petroleum hydrocarbons. However, the effectiveness of biodegradation process can be limited by both contaminant characteristics and its bioavailability in soil. This work aims at establishing a preliminary procedure to identify the main factor (hydrocarbon recalcitrance or its bioavailability) that impairs the biodegradation, possibly resulting in low remediation efficiencies. Tests in soil microcosms were carried out applying biostimulation and bioaugmentation techniques. Similar experiments were conducted using liquid medium containing crude oil and microorganisms, both of them extracted from a weathered contaminated soil sample, nutrients and microbial inoculum constituted of Rhodoturula glutinis and Nocardia nova. After 30 days, highest microcosms biodegradation levels (98.8\%) were obtained with bioaugmentation in liquid medium, pointing out that the main problem of petroleum hydrocarbon utilization by microorganisms was associated to its availability and not only to the intrinsic recalcitrancy of remaining pollutants.

Keywords: bioremediation, bioavailability, petroleum contaminated soil

\section{Introduction}

Recent oil spill occurrences in clay bearing Brazilian tropical soils are motivating studies involving bioreme-

*e-mail: arizzo@cetem.gov.br diation process. This technology accelerates the naturally occurring biodegradation under optimized conditions through adequate oxygen supply and mixing, by adjusting temperature, $\mathrm{pH}$ and water content, performing nutrients amendment (biostimulation) or adding a suitable microbial population (bioaugmentation). This alternative is extremely 
attractive due to its cost effectiveness and the possibility of pollutant mineralization to $\mathrm{CO}_{2}$ and $\mathrm{H}_{2} \mathrm{O}$ by the aerobic metabolic pathway. ${ }^{1}$

It is known that the biological treatment of an oilcontaminated soil can be affected by the hydrocarbons structure and by the weathering processes, which decrease the bioavailability of pollutants to microorganisms. Weathering refers to the result of biological, chemical and physical processes that can affect the type of hydrocarbons that remain in soil, enhance the sorption of hydrophobic organic contaminants (HOCs) over the soil matrix and, consequently, decreases the rate and extent of biodegradation. ${ }^{2,3}$ As a general rule, only the fraction of HOCs dissolved in the aqueous phase is available for microbiological degradation while the sorbed fraction has a low bioavailability. ${ }^{4}$ Moreover, a weathered oil-contaminated soil normally contains recalcitrant fraction of compounds composed, basically, by high molecular weight hydrocarbons (higher than C25 compounds), which could not be easily degraded by indigenous microorganisms. In contrast, a recently oilcontaminated soil contains a higher amount of saturated and aliphatic compounds, which are the most susceptible to the microbial degradation.

Concerns about the possibility of soil contamination due to activities of petroleum industry motivated a partnership between two Brazilian research, which had, as the main objective, the proposal of a new ex-situ bioremediation technology to be applied to Brazilian clay bearing polluted soils. During the course of the project a large number of bioremediation experiments were conduct, most of them in soil microcosms, in order to establish the best strategies and operational conditions to be applied in this contaminated soil. This included, for example, using of bioaumentantion and/ or biostimulation techniques, evaluation of the optimal moisture content and $\mathrm{pH}$ that stimulates de microbial activity, and so on. ${ }^{5-7}$ Nevertheless, the results obtained in terms of organic pollutants removal (expressed as total petroleum hydrocarbon -TPH- removal) and biodegradation efficiency (based on the carbon dioxide generation as a result of aerobic metabolism) were considered low, ranging from 5 to $50 \%$ and 5 to $14 \%$, respectively.

Taking into account these results and those reported in the literature, the reduced effectiveness of the bioremediation process, in soil microcosms, could be related to two possible factors: the pollutants chemical structure or its low bioavailability in soil. But, how to identify which factor, in this specific case, impairs the bioremediation process? With this purpose, a simple methodology, based only in carbon dioxide $\left(\mathrm{CO}_{2}\right)$ quantification, was employed to evaluate organic contaminants' degradation in liquid and in solid phases. The tests aims at identifying the biodegradation extent in both cases and indicate the major factor that interferes in the process.

The present work aims at establishing a preliminary procedure to identify the main factor (hydrocarbon recalcitrance or its bioavailability) that impairs the biodegradation of a weathered crude oil present in a Brazilian contaminated soil (representative of a real situation; five years of contamination; heavy oil), resulting in low remediation efficiencies. Microcosms degradation studies were carried out applying biostimulation and bioaugmentation techniques. In addition, similar experiments were conducted using liquid medium containing crude oil and microorganisms, both of them extracted from contaminated soil sample, adding nutrients and microbial inoculum constituted of Rhodoturula glutinis and Nocardia nova.

\section{Experimental}

\section{Soil}

The soil investigated was a Brazilian clay bearing soil contaminated with heavy crude oil, approximately five years ago, from São Paulo State, Brazil. The authors obtained some physicochemical characteristics of contaminated soil previously and the background information are summarised in Table $1 .^{5}$

Table 1. Background physicochemical characteristics of soil

\begin{tabular}{|c|c|}
\hline Parameters & Value \\
\hline $\mathrm{pH}$ & 5.1 \\
\hline Water Holding Capacity - WHC / (\%) & 38.5 \\
\hline TPH's / $\left(\mathrm{g} \mathrm{kg}^{-1}\right)$ & 26.26 \\
\hline PAH's / ( $\left.\mathrm{g} \mathrm{kg}^{-1}\right)$ & 4.37 \\
\hline Organic matter / $(\%)$ & 8.54 \\
\hline Saturated / (\%) & 23.76 \\
\hline Aromatic / (\%) & 23.46 \\
\hline Resins / (\%) & 52.78 \\
\hline $\mathrm{P} /\left(\mathrm{g} \mathrm{kg}^{-1}\right)$ & 0.001 \\
\hline $\mathrm{N} /\left(\mathrm{g} \mathrm{kg}^{-1}\right)$ & 1.0 \\
\hline $\mathrm{K} /\left(\mathrm{g} \mathrm{kg}^{-1}\right)$ & 0.084 \\
\hline Particle Size Distribution: Sand / (\%) & 62 \\
\hline Clay / $(\%)$ & 18 \\
\hline Silt / (\%) & 16 \\
\hline
\end{tabular}

A specialised team was in charge of sampling the soil in order to guarantee representative collection of samples, which were stored at $5^{\circ} \mathrm{C}$. Before use, the contaminated soil was mechanically homogenized and quarted to decrease the localized occurrence of elevated contaminant levels. 
In this work the contaminated soil was employed both as a microorganisms and organic extract source.

\section{Oil extract}

The organic extract employed in liquid medium tests (as will be described) was obtained extracting fifty grams of contaminated soil with $n$-hexane (analytical grade) after sonication (Cole-Parmer Instruments, model 8891, USA) for $5 \mathrm{~min}$. Afterwards, the organic extract, composed basically by the residual crude oil and solvent, was firstly concentrated in a rotary evaporator (Yamato, model RE50, Japan) to approximately $10 \mathrm{~mL}$ and than in a heated concentrator with nitrogen flow (Tecnal, model TE019, Brazil) to $2 \mathrm{~mL}$. The final extract was added into the inorganic medium ( $\mathrm{NaCl} 5 \mathrm{~g} \mathrm{~L}^{-1}, \mathrm{~K}_{2} \mathrm{HPO}_{4} 1 \mathrm{~g} \mathrm{~L}^{-1}, \mathrm{NH}_{4} \mathrm{H}_{2} \mathrm{PO}_{4} 1 \mathrm{~g} \mathrm{~L}^{-1}$, $\left.\left(\mathrm{NH}_{4}\right)_{2} \mathrm{SO}_{4} 1 \mathrm{~g} \mathrm{~L}^{-1}, \mathrm{MgSO}_{4} \cdot 7 \mathrm{H}_{2} \mathrm{O} 0.2 \mathrm{~g} \mathrm{~L}^{-1}, \mathrm{KNO}_{3} 3 \mathrm{~g} \mathrm{~L}^{-1}\right)$ to be employed as the principal organic carbon source by the microorganisms during the liquid medium tests. ${ }^{8}$

\section{Inoculum production}

In experiments involving the application of bioaugmentation technique, two different types of inoculum were employed. The first one, called Soil Extracted Microorganisms (SEM), was obtained extracting indigenous microorganisms from fifty grams of contaminated soil sample using $184 \mathrm{~mL}$ inorganic medium under agitation (150 rpm) in shaker apparatus (Nova Ética, mod 430/RD, Brazil) for 2 h. ${ }^{8}$ The suspension was maintained to settle for $2 \mathrm{~h}$ and $46 \mathrm{~mL}$ of supernatant was used for each flask as inoculum. This inoculum was only applied in liquid medium tests, in order to reproduce the same amount of microorganisms present in soil samples used in soil microcosms tests.

As previously reported by authors, the contaminated soil used in this work had a heterotrophic microorganisms and oil-degrading microroganisms of approximately $10^{5} \mathrm{CFU}$ g soil ${ }^{-1}$ and $10^{4}$ MPN g soil ${ }^{-1}$, respectively. ${ }^{6,7}$

A second inoculum type, called Hydrocarbon Degrader Consortium (HDC), was used in both testes such as soil microcosms and liquid medium. These inoculum was constituted by two crude oil-degrading microorganisms (Nocardia nova and Rhodotorula glutinis var. dairenesis), previously isolated from the crude oil contaminated soil. ${ }^{6}$ Cells were grown in mineral medium containing crude oil $(4 \% \mathrm{v} / \mathrm{v})$ as the sole carbon source, centrifuged and washed twice with sterile saline solution $(0.7 \%)$, as described by Trindade et al..$^{7}$ Inoculum was added to the soil samples in order to get the concentration of $10^{8} \mathrm{CFU}$ (Colony Forming Unit) $g$ of soil $^{-1} \cdot 6,7$

\section{Biodegradation experiments}

\section{Liquid medium tests}

Liquid medium tests were carried out trying to maximize the oil bioavailability, through mass transfer improvement.

Experiments were carried out in $250 \mathrm{~mL}$ hermetically stopper Pyrex filter flask, containing a final volume of $50 \mathrm{~mL}$, including inorganic medium, oil extract and microbial inoculum.

Specific conditions tested are described as ${ }^{8}(i)$ condition 1: Inorganic medium $(48 \mathrm{~mL})$ and oil extract $(2 \mathrm{~mL}, 4 \%$ $\mathrm{v} / \mathrm{v})$; (ii) condition 2: Inorganic medium with Soil Extracted Microorganisms (SEM) $(48 \mathrm{~mL})$ and oil extract $(2 \mathrm{~mL}$, $4 \% \mathrm{v} / \mathrm{v}$ ); (iii) condition 3: Inorganic medium with SEM (46 mL), oil extract ( $2 \mathrm{~mL}, 4 \% \mathrm{v} / \mathrm{v})$ and inoculum of HDC $(2 \mathrm{~mL})$ and $(i v)$ condition 4: Inorganic medium (46 mL), oil extract $(2 \mathrm{~mL}, 4 \% \mathrm{v} / \mathrm{v})$ and inoculum of Hydrocarbon Degrader Consortium (HDC) (2 mL).

All conditions were performed in duplicates and flasks were incubated at $30{ }^{\circ} \mathrm{C}$ for 30 days. In order to keep sufficient oxygen concentration, periodical renewals (in $48 \mathrm{~h}$ intervals) of flasks headspaces were made by opening and aerating for $2 \mathrm{~min}$. During these experiments, the microbial activity was monitored by carbon dioxide production.

\section{Soil microcosms tests}

The best strategies for biostimulation, bioaugmentation and moisture adjustment applied in the biological treatment of the Brazilian contaminated soil investigated in this paper were established in previous works. ${ }^{5,7}$ Some of those strategies were employed in soil microcosms tests described bellow.

Biodegradation experiments in soil microcosms were carried out in $250 \mathrm{~mL}$ hermetically stopper Pyrex filter flask, containing $50 \mathrm{~g}$ of soil and others additives such as nutrients and inoculum. Soil moisture and $\mathrm{pH}$ were adjusted to $50 \%$ of water holding capacity (WHC) and 7.0, respectively.

Specific conditions used for each sample are described as $(i)$ condition 1: Contaminated soil, $\mathrm{K}_{2} \mathrm{HPO}_{4}(\mathrm{C}: \mathrm{P}$ relation 100:1), inoculum of HDC (2 mL); (ii) condition 2: Contaminated soil, $\mathrm{K}_{2} \mathrm{HPO}_{4}(\mathrm{C}: \mathrm{P}$ relation 100:1).

All conditions were performed in duplicates and flasks were incubated at $30{ }^{\circ} \mathrm{C}$ for 30 days. Similarly to the procedure adopted in the liquid medium test, oxygen supply was guaranteed by periodical renewals (in 48 intervals) of flasks headspaces. Also in these experiments, the microbial activity was monitored by carbon dioxide production, as done in liquid medium tests. 


\section{Quantitative $\mathrm{CO}_{2}$ determination}

In present study the examination of the biodegradation process was only accomplished by crude oil losses calculated from the gas chromatographic measurement of $\mathrm{CO}_{2}$ evolved, since it is considered by different authors as a direct proof of complete mineralization of the organic contaminant. ${ }^{9-12}$ As reported by Heitzer and Sayler, while pollutants and intermediates are important chemical monitoring parameters, only the formation of end products such as $\mathrm{CO}_{2}$ provides direct proof of the complete destruction and mineralization of a pollutant. ${ }^{13}$

A Hewlett-Packard 5890A II gas chromatograph was used to analyze the headspaces from hermetically stopper Pyrex filter flask containing soil and liquid samples. The carrier gas was ultra-high purity helium. A thermal conductivity detector (TCD) was set at $220^{\circ} \mathrm{C}$ and a CHROMOSORB 102 column were used. The gas confined in Pyrex filtering flasks was sampled, using a gas-tight syringe, in volume of $500 \mu \mathrm{L}$ through the suction of the internal atmosphere of the flasks headspace before the aerating process.

It could be assumed that, as a consequence of the heterotrophic aerobic metabolisms of the microorganisms, if two moles of organic carbon are consumed (from the weathered oil or from the soil natural organic matter), one carbon mol is employed in $\mathrm{CO}_{2}$ generation, and the second carbon mol is incorporated into the biomass. So, the $\mathrm{CO}_{2}$ quantified by gas chromatography represents only $50 \%$ of the total organic matter that was biodegraded. Based on this concept and using the accumulated value of $\mathrm{CO}_{2}$ generated during 30 days of the experiments, the biodegradation efficiency $(\mathrm{BE})$ was calculated as: $\mathrm{BE} \%=$ (Totally biodegraded carbon) $\times 100 /$ Total organic carbon in the soil; Totally biodegraded carbon $=2 \times$ Carbon from $\mathrm{CO}_{2}$ generated during 30 days. ${ }^{7}$

It is also frequently assumed that the total organic carbon corresponds to 80 to $90 \%$ of total petroleum hydrocarbon content in the contaminated soil with crude oil. Taking this into account it is possible to confirm in Table 1 that the value obtained for organic carbon $\left(\mathrm{C}_{\text {organic }}\right)$ corresponds to $89 \%$ of the Total Petroleum Hydrocarbon (TPH) present in the weathered contaminated soil. So, in this work, it was considered that: total organic carbon in the soil $=85 \%$ of soil TPH concentration at the beginning of the experiment. ${ }^{7}$

\section{Results and Discussion}

The $\mathrm{CO}_{2}$ chromatographic quantification accomplished during the biodegradation experiments in liquid medium allowed the evaluation of the $\mathrm{CO}_{2}$ generation profile for each condition (Figure 1).

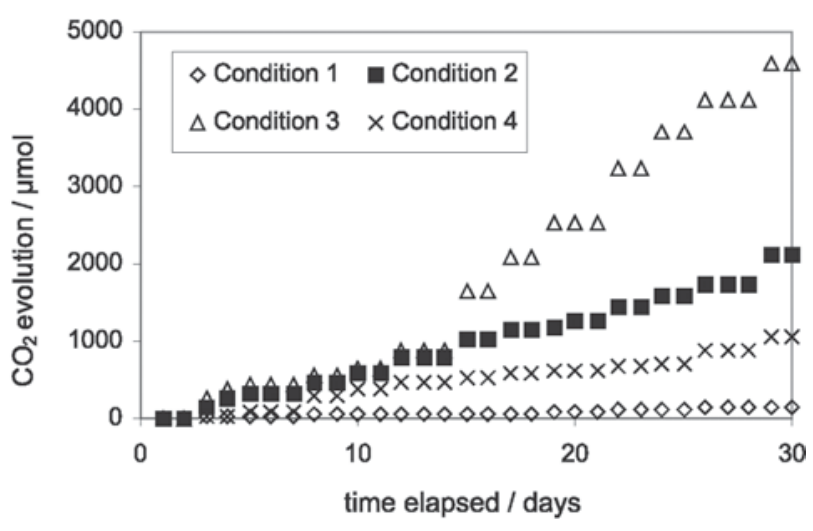

Figure 1. Profiles of $\mathrm{CO}_{2}$ evolution for liquid medium tests.

It could be observed that during the first 15 days, that the curves behaviour of conditions 2, 3 and 4 were similar, indicating an adaptation period for both type of the inoculum added: soil extracted microorganisms (SEM) and hydrocarbon degrader consortium (HDC).

The $\mathrm{CO}_{2}$ evolution after the 15 th day was higher in conditions 2 and 3 than in condition 4, possibly due to the previous acclimatisation period that the extracted microbiota passed during over 4 years of contamination and to the strong interaction between different native microbial species.

Such behaviour could be confirmed in Table 2 where the biodegradation efficiencies (BE \%) obtained after 30 days are presented.

Table 2. Biodegradation Efficiencies (BE, \%) obtained in liquid medium tests

\begin{tabular}{cc}
\hline Condition tested & $\mathrm{BE} /(\%)$ \\
\hline 1 & 3 \\
2 & 45 \\
3 & 98 \\
4 & 23 \\
\hline
\end{tabular}

It is possible to note in Table 2 that inoculum provided by SEM was capable to degrade, in liquid medium, $45 \%$ of the contaminant (condition 2), while the HDC inoculum alone (condition 4 ) presents a BE of only $23 \%$. When the hydrocarbon degrader microbial consortium was introduced in liquid medium jointly with the soil extracted microorganisms (indigenous microorganisms, condition 3) a BE of $98 \%$ was obtained. This result indicates that the synergic effect obtained by the addition of the degrader inoculum was extremely important towards oil biodegradation target.

The $\mathrm{CO}_{2}$ generation profile using soil microcosms for the two conditions tested are presented in Figure 2. The 
biodegradation efficiencies (BE) for the bioestimulated system, containing indigenous microorganisms (condition 2), and the bioaugmented one (condition 1), containing HDC inoculum (Rhodotorula glutinis and Nocardia nova) were 8 and $13 \%$, respectively. Comparing the results obtained for equivalent conditions in liquid medium and in soil microcosms (condition 2 in liquid medium test with condition 2 in soil microcosms and condition 3 in liquid medium test with condition 1 in soil microcosms), it is possible to verify the significant improvement in BE as a result of oil bioavailability. In liquid medium it is verified an increase of six times in BE specifically when only the indigenous microbial population was used $(8 \%$ in soil and $45 \%$ in liquid medium). On the same way, in the case where the indigenous microbial population was supplemented with HDC inoculum, the BE had an increase of 7.5 times (16\% in soil to $98 \%$ in liquid medium).

These results indicate that the low values obtained for BE in soil could be related with the strong interaction between contaminant and soil, reducing the oil bioavalilability, and it is not a direct consequence of oil recalcitrance.

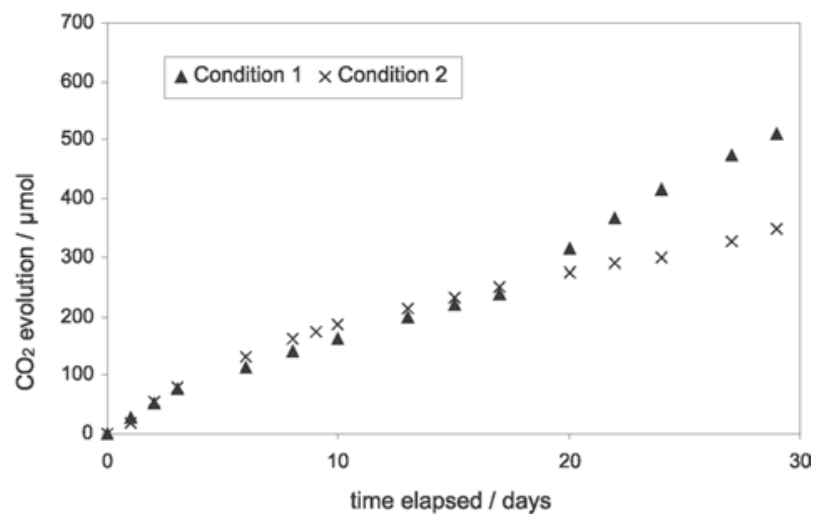

Figure 2. Profiles of $\mathrm{CO}_{2}$ evolution for soil microcosms tests.

Historically, contaminated aged samples where contact times may range from months to years, or even decades, usually concentrate some pollutants that are slowly biodegraded. Additionally, the aging (or weathering) process contributes to the sorption of this organic matter, thus reducing its bioavailability and, consequently, its biodegradation. The extent of bioavailability reduction during aging is dependent on the contaminant concentration, the aging conditions, and sample characteristics: sequestration is more extensive at low contaminant concentrations; occurrence of wetting and drying cycles increase the extent of sequestration; and both the rate and the extent of sequestration may vary markedly among different soil and sediment samples. ${ }^{14}$ Biodegradation rates are usually higher in sandy soils than in clayey soils. Additionally the decrease of bioavailability may result from incorporation of the pollutant to the soil organic material due to chemical oxidation reactions, as well slow diffusion into very small pores, both sorption into organic matter and formation of semi-rigid films around non-aqueous-phase liquids, thus causing a high resistance to the mass transfer. ${ }^{7}$ Estimations of the bioavailability fraction in feasibility studies conducted prior to a bioremediation project may represent an useful estimation of the maximum achievable biodegradation level.

Loehr et al. ${ }^{2}$ showed that one soil containing aged crude oil was not able to be remediated using solid-phase bioremediation process. Although substantial concentrations of hydrocarbons remained in this soil, it was demonstrated that those hydrocarbons were highly weathered and unable to be released from the soil. Thus, the fraction of chemical remaining in the soil after biodegradation (even if that fraction is close to $100 \%$ ) can represent an environmentally acceptable endpoint (EAE). ${ }^{14}$ Such endpoint occurs when the chemicals that remains in soil do not have an adverse impact on human health and the environment, and any chemicals that could be slowly released from will be mainly degraded by natural assimilative capacity of the soil. ${ }^{7}$ As reported by Trindade et al., ${ }^{7}$ the EAE concept recognise that high concentrations of chemical in soil may not be associated with adverse effects. At a site with contaminated soil, risk to human health and the environment is related directly to the release and availability of a chemical and the knowledge of what is released and the rate of releasing is so important as the type and concentration of pollutant.

\section{Conclusions}

The biodegradation efficiencies (BE) values obtained in liquid medium experiments using both indigenous microorganisms and hydrocarbon degrader consortium (HDC) inoculum showed that, probably, the main impairing factor to oil biodegradation present in the studied clay bearing Brazilian soil could be attributed to the strong interaction between the contaminant and the soil matrix, as a consequence of the weathering process.

Further bioaugmentation experiments in soil microcosms must be performed using a higher inoculum density constituted of indigenous microorganisms and hydrocarbon degrader microorganisms since it was verified a positive synergistic effect in liquid medium.

Nevertheless, it should be observed limitations when considering the weathered fraction of contaminant that remains in soil as an environmental acceptable endpoint (EAE).

Different technologies or strategies to increase the bioavailability of oil in soils can be applied, even by physical 
(by grinding or mixing) or chemical means (surfactants, co-solvents or chelating agents addition). In both cases, the main goal is to increase mass transfer from the sorbed phase, thus enhancing the residual oil solubility. ${ }^{15}$

It is important to keep in mind that, although employing toxicological and agricultural sciences, the concept of bioavailability has recently call the attention from industrial and environmental sectors as an important consideration for deciding how to treat (biologically or chemically) and how to fix the clean up endpoints. In the last case, the rationale is that if contaminants in soil are not bioavailable, more contaminant mass can be left in place or be untreated without creating additional risk. So, it is possible to achieve cost and time savings with a bioavailability study. ${ }^{15}$

In this sense, the present work gave a initial contribution while established a preliminary procedure to identify the main factor (hydrocarbon recalcitrance or its bioavailability) that limits the biodegradation of a weathered crude oil present in a Brazilian clay bearing soil.

\section{Acknowledgments}

This work was supported by Center for Mineral Technology (CETEM) in partnership with CENPESPETROBRAS.

\section{References}

1. Cunha, C. D.; MSc Dissertation, Universidade Federal do Rio de Janeiro, Brazil, 1996.

2. Loehr, R. C.; McMillen, S. J.; Webster, M. T.; Pract. Periodical Hazard., Toxic., Radioact. Waste Manage. 2001, 5, 78.
3. Bosma, T. N. P.; Middeldorp, P. J. M.; Schraa, G.; Zehnder, A. J. B.; Environ. Sci. Technol. 1997, 31, 248.

4. Allan, K. A.; Herbert, B. E.; Morris, P. J.; Mcdonald, T. J.; In Situ and On-Site Bioremediation 1997, 5, 629.

5. Rizzo, A. C. L.; Santos, R.; Soriano, A. U.; Seabra, P. N.; Leite, S. G. F.; Proceedings of the Fourth International Congress on Environmental Geotechnics (4 ${ }^{\text {th }}$ ICEG), Rio de Janeiro, Brazil, 2002.

6. Sá, M. C. C.; M. Sc. Dissertation, Universidade Federal do Rio de Janeiro, Brazil, 2002.

7. Trindade, P. V. O.; Sobral, L. G.; Rizzo, A. C. L.; Leite, S. G. F.; Soriano, A. U.; Chemosphere 2005, 58, 515.

8. Vecchioli, G. L.; Del Panno, M. T.; Painceira, M. T.; Environ. Pollut. 1990, 67, 249.

9. Troquel, J.; Larroche, C.; Dussap, C. G.; Biochem. Eng. J. 2003, 13,103 .

10. Gibb, A.; Chu, A.; Wong, R. C. K.;Goodman, R. H.; J. Biorem. Eng. 2001, 127, 818.

11. Noncentin, M.; Pinelli, D.; Fava, F.; Chemosphere 2000, 41, 1115.

12. Solano-Serena, F.; Marchal, R ; Blanchet, D.; Vandecasteele, J.P.; Biodegradation 1998, 9, 319.

13. Heitzer, A.; Sayler, G.S.; Trends Biotechnol. 1993, 11, 334.

14. Cuypers, C.; Ph.D. Thesis, Wageningen University, The Netherlands, 2001.

15. Ehlers, L. J.; Luthy, R. G.; Environ. Sci. Technol. 2003, 302A.

Received: January 22, 2007

Published on the web: January 30, 2008 